NBER WORKING PAPER SERIES

\title{
HOW UNOBSERVABLE PRODUCTIVITY BIASES THE VALUE OF A STATISTICAL LIFE
}

\author{
Thomas J. Kniesner \\ W. Kip Viscusi \\ Christopher Woock \\ James P. Ziliak \\ Working Paper 11659 \\ http://www.nber.org/papers/w11659
}

\author{
NATIONAL BUREAU OF ECONOMIC RESEARCH \\ 1050 Massachusetts Avenue \\ Cambridge, MA 02138 \\ September 2005
}

Cogan Professor of Law and Economics, Harvard Law School, Hauser 302, Cambridge, MA 02138 ph: (617) 496-0019kip@law.harvard.edu. Address correspondence to tkniesne@maxwell.syr.edu. We are grateful to the U.S. Bureau of Labor Statistics for providing proprietary data on fatality rates. The findings herein do not reflect the opinion of the BLS or any other federal agency. Viscusi's research is supported by the Harvard Olin Center for Law, Economics, and Business. The views expressed herein are those of the author(s) and do not necessarily reflect the views of the National Bureau of Economic Research.

(C2005 by Thomas J. Kniesner, W. Kip Viscusi, Christopher Woock and James P. Ziliak. All rights reserved. Short sections of text, not to exceed two paragraphs, may be quoted without explicit permission provided that full credit, including (C) notice, is given to the source. 
How Unobservable Productivity Biases the Value of a Statistical Life

Thomas J. Kniesner, W. Kip Viscusi, Christopher Woock and James P. Ziliak

NBER Working Paper No. 11659

September 2005

JEL No. I10, J17, J28, K00

\section{$\underline{\text { ABSTRACT }}$}

A prominent theoretical controversy in the compensating differentials literature concerns unobservable individual productivity. Competing models yield opposite predictions depending on whether the unobservable productivity is safety-related skill or productivity generally. Using five panel waves and several new measures of worker fatality risks, first-difference estimates imply that omitting individual heterogeneity leads to overestimates of the value of statistical life, consistent with the latent safety-related skill interpretation. Risk measures with less measurement error raise the value of statistical life, the net effect being that estimates from the static model range from $\$ 5.3$ million to $\$ 6.7$ million, with dynamic model estimates somewhat higher.

Thomas J. Kniesner

Center for Policy Research

426 Eggers Hall

Syracuse University

Syracuse, NY 13244-1020

tkniesne@maxwell.syr.edu

W. Kip Viscusi

Harvard Law School

1575 Massachusetts Avenue

Cambridge, MA 02138

and NBER

kip@law.harvard.edu

Christopher Woock

Department of Economics

University of Kentucky

Lexington, KY 40502
James P. Ziliak

University of Kentucky

Department of Economics

Lexington, KY 40502 


\section{How Unobservable Productivity Biases the Value of a Statistical Life}

Thomas J. Kniesner, W. Kip Viscusi, Christopher Woock, James P. Ziliak

(C) 2005 Thomas J. Kniesner, W. Kip Viscusi, Christopher Woock, James P. Ziliak. All rights reserved.

\section{Introduction}

Worker heterogeneity has played a prominent role in the compensating differentials literature. There could be heterogeneity in tastes where workers differ in willingness to accept risk for a given set of market opportunities. There could also be heterogeneity in productivity affecting the worker's safety-related productivity or market productivity more generally. We examine econometrically the implications of individual heterogeneity for estimates of the value of a statistical life (VSL) and in the process establish that some key anomalous results in the literature disappear when panel data and appropriate econometric estimators are combined to estimate VSL. Our panel estimates also resolve an ongoing theoretical debate regarding the direction of bias in labor market estimates of VSL, indicating that the Shogren and Stamland (2002) assessment of the effect of differences in tastes and safety-related productivity is the dominant empirical influence.

By itself, preference heterogeneity presents little trouble for hedonic wage theory. Suppose all workers face the same market offer curve in terms of the maximum available wage for any given level of job risk. If workers had homogeneous tastes we would then observe a single wage-risk combination in the market, which reduces the empirical task to estimating the equilibrium point. With heterogeneous tastes workers will settle along 
different points of the market opportunities curve, and we will observe a set of market equilibria for different workers. When preferences are heterogeneous the hedonic wage equation then traces out the set of market equilibria reflecting the various points of tangency between the market offer curve and workers' constant expected utility loci.

Matters become more complex if there are unobservable aspects of worker productivity. If general labor market productivity is unobservable, Hwang, Reed, and Hubbard (1992) theorize that typical estimates of compensating differentials will understate workers' valuation of risk. In an illustrative example using the VSL estimates of Thaler and Rosen (1976), Hwang et al. calculate that typical econometric estimates of the value of a statistical life could be too low by as much as 90 percent due to latent worker productivity differences.

Instead of overall productivity differences there may be heterogeneous attitudes toward risk along with what might be called safety-related productivity as workers may differ in their riskiness within any particular job (Viscusi and Hersch 2001). Suppose that firms do observe but researchers do not observe safety-related productivity. The information asymmetry means that workers will face different market offer curves based on their safety-related productivity, in contrast to the usual empirical assumption of a common offer curve. In the absence of variables correlated with riskiness, such as smoking status, econometric estimates will not then be tracing out equilibria off a single offer curve, as in the standard hedonic wage theory, but rather points off different market offer curves when safety-related productivity differs. If econometric estimates do not account for the influences of latent safety-related productivity, the resulting VSL estimates will be biased. 
Shogren and Stamland (2002) examine how the bias generated by ignoring unobservable differences in safety-related productivity may affect VSL estimates. Their research considers the role of heterogeneity in worker preferences as well as what they term skill, which parallels safety-related productivity (Viscusi and Hersch 2001) rather than overall market productivity (Hwang, Reed, and Hubbard 1992). In Shogren and Stamland's approach both skill and preferences are unobservables, which leads to an upward bias in estimates of the value of a statistical life unless very strong special conditions are met. The practical result in their illustrative simulations is that available market estimates of the value of a statistical life may overstate the true value by several times. Both Hwang, Reed, and Hubbard (1992) and Shogren and Stamland (2002) theorize that conventional VSL estimates could be biased by a substantial amount, but they hypothesize different directions of bias. Shifting the focus from overall market productivity to safety-related skill reverses the expected direction of the bias from being an underestimate of VSL to being an overestimate of VSL.

Most econometric research to date has used cross-sectional data, which limit the ability to control for the unobserved worker heterogeneity that can lead to the large under- or over-estimates of VSL that have worried many researchers. Here we demonstrate how micro panel data used with appropriate econometric treatment of latent heterogeneity remove the biases that have concerned researchers such as Huang, Reed, and Hubbard (1992), Viscusi and Hersch (2001), and Shogren and Stamland (2002). Our treatment of individual heterogeneity is quite general, encompassing differences in traditional labor market productivity, differences in safety-related skill, and heterogeneity in tastes. The static model estimates range from $\$ 5.3$ million to $\$ 6.7$ million with 
dynamic model estimates somewhat higher. Comparing our results using best econometric practices with results from more conventional models indicates situations where the value of life is over- versus under-estimated. VSL is overestimated by up to a factor of four when measurement errors are ignored and heterogeneity is omitted. VSL is underestimated by up to a third when measurement error is ignored and heterogeneity is included but improperly modeled as an uncorrelated random effect.

\section{Econometric Framework}

Our empirical research begins with the canonical hedonic wage equation used in the value of statistical life literature. For worker $i(i=1, \ldots, N)$ in industry $j(j=1, \ldots, J)$ and occupation $k(k=1, \ldots, K)$ at time $t(t=1, \ldots, T)$ the hedonic tradeoff between the wage and risk of fatality is

$$
\ln w_{i j k t}=\alpha \text { fatal }_{j k t}+X_{i j k t} \gamma+\delta_{t}+u_{i j k t},
$$

where $\ln w_{i j k t}$ is the natural $\log$ of the hourly wage rate, fatal $_{j k t}$ is the industry and occupation specific fatality rate, $X_{i j k t}$ is a vector containing dummy variables for the worker's one-digit occupation (and industry in some specifications) and region of residence as well as usual demographic variables: worker education, age, race, marital status, and union status. Finally, $\delta_{t}$ is a vector of time effects, and $u_{i j k t}$ is an error term allowing conditional heteroskedasticity and within industry-by-occupation autocorrelation. $^{1}$

\footnotetext{
${ }^{1}$ We adopt a parametric specification of the regression model representing hedonic equilibrium in (1) for comparison purposes with the existing literature. An important emerging line of research is how more econometrically free-form representations of hedonic labor markets facilitates identification of underlying fundamentals, which would further generalize estimates of VSL (Ekeland, Heckman, and Nesheim 2004).
} 


\subsection{Fixed-Effects Estimators}

The standard panel-data estimators permitting fixed effects through personspecific intercepts in (1) are the mean-difference (within) estimator and the timedifference (first-differences) estimator. The fixed effects include all person-specific timeinvariant differences in tastes and all aspects of productivity. The two estimators yield identical results when there are only two time periods and when the number of periods converges towards infinity. With a finite number of periods $(T>2)$ estimates from the two different fixed-effects estimators can diverge due to possible non-stationarity in wages, measurement error, or model misspecification (Wooldridge 2002). Because wages from longitudinal data on individuals have been shown to be non-stationary in other contexts (MaCurdy 1982; Abowd and Card 1989), we adopt the preferred first-difference model.

The first-difference model eliminates any time-invariant effect by estimating the changes over time in hedonic equilibrium

$$
\Delta \ln w_{i j k t}=\alpha \Delta \operatorname{fatal}_{i j k}+\Delta X_{i j k t} \gamma+\tilde{\delta}_{t}+\Delta u_{i j k t},
$$

where $\Delta$ refers to the first-difference operator and $\tilde{\delta}_{t}$ is a re-normalized vector of time dummies. $^{2}$

The first-difference model could exacerbate errors-in-variables problems relative to the within model (Griliches and Hausman (1986). If the fatality rate is measured with a classical error then the first-difference estimate of $\hat{\alpha}$ may be attenuated relative to the

\footnotetext{
${ }^{2}$ We also estimate a dynamic version of (2) by adding $\beta \Delta \ln w_{i j k t-1}$ to the right-hand side and using the firstdifference instrumental variables estimator recommended in Arellano (1989). The estimator uses the twoperiod lagged level of the dependent variable as the identifying instrument for the one-period lagged difference in the dependent variable. The lagged dependent variable controls for additional heterogeneity and serial correlation plus sluggish adjustment to equilibrium. We compare the estimated short-run effect, $\hat{\alpha}$, to the estimated long-run effect, $(\hat{\alpha} / 1-\hat{\beta})$ and their associated VSLs.
} 
within estimate. An advantage of the regression specification in (2), which considers intertemporal changes in hedonic equilibrium outcomes, arises because we can use socalled wider ( $2+$ year) differences. If $\Delta \geq 2$ then measurement error effects are mitigated in (2) relative to fixed-effects mean differences regression (Griliches and Hausman 1986). As discussed in the data section below we address the measurement error issue in the fatality rate by employing multi-year averages of fatalities. For completeness we also note how the first-difference estimates compare to the within estimates.

\subsection{Comparison Estimators}

If $E\left[u_{i j k} \mid\right.$ fatal $\left._{j k}, X_{i j k}\right]=0$, which is the standard zero conditional mean assumption of least squares regression, then OLS estimation of the hedonic equilibrium in (1) using pooled cross-section time-series data is consistent. If the zero conditional mean assumption holds, which is unlikely to be the case, it implies that the two estimators frequently employed with panel data, the between-groups estimator and the random-effects estimator, will yield consistent coefficient estimates.

The between-groups estimator is a cross-sectional estimator using individuals' time-means of the variables

$$
\overline{\ln w_{i j k}}=\alpha \overline{\text { fatal }_{j k}}+\overline{X_{i j k}} \gamma+\bar{\delta}+\overline{u_{i j k}}
$$

where $\overline{\ln w_{i j k}}=\frac{1}{T} \sum_{t=1}^{T} \ln w_{i j k t}$ and other variables similarly defined. A potential advantage of the between-groups estimator is that measurement-error induced attenuation bias in estimated coefficients may be reduced because averaging smoothes the data generating process. Because measurement error affects estimates of the VSL (Black and Kniesner 
2003), the between-groups estimator is likely to provide improved estimates of the wagefatal risk tradeoff over OLS estimates of equation (1).

The random-effects model differs from the OLS and fixed-effects models in (1) and (2) by specifying components of the overall error as $u_{i j k t}=\mu_{i}+v_{i j k t}$, where $\mu_{i}$ is person-specific and time-invariant unobserved heterogeneity, and $v_{i j k t}$ is an independently and identically distributed random error component. The random-effects estimator is a weighted average of the between-groups variation and the within-groups variation.

Consistency of the random-effects estimator requires $E\left[\mu_{i} \mid\right.$ fatal $\left._{j k t}, X_{i j k t}\right]=0$ and $E\left[v_{i j k t} \mid\right.$ fatal $\left._{j k t}, X_{i j k t}\right]=0$. The first condition implies that the time-invariant unobserved heterogeneity is randomly distributed in the population. The implication is that selection into possibly risky occupations and industries on the basis of unobserved productivity and tastes is purely random across the population of workers. Although both the pooled least squares and between-groups estimators remain consistent in the presence of random heterogeneity, the random-effects estimator will be more efficient because it accounts for person-specific autocorrelation in the wage process.

If selection into a particular industry and occupation is not random with respect to time-invariant unobserved productivity and risk preferences, then estimates of the VSL based on the pooled cross-section, between-groups, or random-effects estimators will be biased and inconsistent. Indeed, Shogren and Stamland (2002) indicate that the bias will be positive and that failure to account for non-random time-invariant safety-related skill 
(fixed effects) will lead to substantially upward-biased estimates of the VSL based on labor-market wage data. ${ }^{3}$

\subsection{Research Objective}

The focal parameter of interest in each of the regression models we estimate is $\hat{\alpha}$, which is used in constructing estimates of the value of a statistical life. Accounting for the fact that fatality risk is per 100,000 workers and that the typical work-year is about 2000 hours, the estimated value of a statistical life at the mean level of wages is

$$
\overline{V S L}=\left[\frac{\partial \hat{w}}{\partial f a t a l}=\hat{\alpha} \times \bar{w} \times 2000 \times 100,000\right] .
$$

Although the VSL function in (4) can be evaluated at various points in the wage distribution, most studies report only the mean effect. To highlight the differences in estimates of the VSL with and without controls for unobserved individual differences, we follow the standard convention of focusing on $\overline{V S L}$ in our estimates presented below.

\section{Data and Sample Descriptions}

The main body of our data come from the 1993-2001 waves of the Panel Study of Income Dynamics (PSID), which provides individual-level data on wages, industry and occupation, and demographics. The PSID survey has followed a core set of households since 1968 plus newly formed households as members of the original core have split off into new families.

\footnotetext{
${ }^{3}$ Aside from nonrandom selection based on time-invariant skills, it is possible for workers to self select into a given industry based on unobserved time-varying factors related to the business cycle. Keane (1993) examined the issue as a possible explanation for movements in inter-industry wage differentials over the business cycle using data from the National Longitudinal Survey of Young Men (there were no controls for fatal risk). He found that controlling for the fixed effect was important but, conditional on the timeinvariant skill, there was no evidence of nonrandom selection based on time-varying unobserved factors. Based on Keane's evidence we make the absence of nonrandom selection base on time-varying unobservables a maintained assumption in our model.
} 


\subsection{PSID Sample}

The sample we use consists of male heads of household ages 18-65 who (i) are in the random Survey Research Center (SRC) portion of the PSID, and thus excludes the oversample of the poor in the Survey of Economic Opportunity (SEO) and the Latino sub-sample, (ii) worked for hourly or salary pay at some point in the previous calendar year, (iii) are not permanently disabled or institutionalized, (iv) are not in agriculture or the armed forces, (v) have a real hourly wage greater than $\$ 2$ per hour and less than $\$ 100$ per hour, and (vi) have no missing data on wages, education, region, industry, and occupation.

Beginning in 1997 the PSID moved to every other year interviewing; thus, for consistent spacing of survey response we use data from the 1993, 1995, 1997, 1999, and 2001 waves. Importantly, we do not require individuals to be present for the entire sample period; that is, we have an unbalanced panel where we assume that missing values are random events. ${ }^{4}$ Our sample filters yield 2,108 men and 7,937 person-years. Just over 40 percent of the men are present for all five waves (nine years) and another 25 percent are present for at least four waves.

The focal variable from the PSID in our models of hedonic labor market equilibrium is the hourly wage rate. For workers paid by the hour the survey records the gross hourly wage rate. The interviewer asks salaried workers how frequently they are paid, such as weekly, bi-weekly, or monthly. The interviewer then norms a salaried worker's pay by a fixed number of hours worked depending on the pay period. For

\footnotetext{
${ }^{4}$ In the event that item or panel nonresponse is not random then least squares estimates of the model parameters may be biased. However, Ziliak and Kniesner (1998) show that in the case of labor market behavior the propensity to attrite is well captured by a time-invariant and person-specific fixed effect. If such nonrandom attrition is present our differenced model in (2) should sweep it out along with the other time-invariant factors.
} 
example, salary divided by 40 is the hourly wage rate constructed for a salaried worker paid weekly. We deflate this nominal wage by the personal consumption expenditure deflator for 2001 base year. We then take the natural log of the real wage rate to minimize the influence of outliers.

The demographic controls in the model include years of formal education, a quadratic in age, dummy indicators for region of country (northeast, north central, and west with south the omitted region), race (white $=1$ ), union status (coverage $=1$ ), marital status (married $=1)$, and one-digit occupation. Table 1 presents summary statistics for the main variables of interest.

\subsection{Fatality Risk Measures}

The fatality risk measure we use is the fatality rate for the worker's two-digit industry by one-digit occupation group. In particular, we distinguished 720 industryoccupation groups using a breakdown of 72 two-digit SIC code industries and the 10 onedigit occupational groups. Constructing codes for two-digit industry by one-digit occupation in the PSID we then matched each worker to the relevant industry-occupation fatality risk.

We constructed a worker fatality risk variable using proprietary U.S. Bureau of Labor Statistics data from the Census of Fatal Occupational Injuries (CFOI) for 19922002. ${ }^{5}$ The CFOI provides the most comprehensive inventory to date of all work-related fatalities. The CFOI data come from reports by the Occupational Safety and Health Administration, workers' compensation reports, death certificates, and medical examiner

\footnotetext{
${ }^{5}$ The fatality data are not publicly available, but can be obtained on CD-ROM via a confidential agreement with the U.S. Bureau of Labor Statistics. Our variable construction procedure follows that in Viscusi (2004), who also compares the fatality risk measure to other death risk variables.
} 
reports. In each case there is an examination of the records to determine that the fatality was in fact a job-related incident.

We focus on three measures of fatal risk, which differ in construction of the numerator. The first measure simply uses the number of fatalities in each industryoccupation cell. The second measure uses a three-year average of fatalities surrounding each PSID survey year (1992-1994 for the 1993 wave, 1994-1996 for the 1995 wave, and so on). The third measure uses the 11-year average (1992-2002) of fatalities in each industry-occupation cell. The denominator for each measure used to construct the fatality risk is the number of employees for that industry-occupation group in survey year $t$; that is, all three measures of the fatality risk are time-varying -- the first two because of changes in both the numerator and the denominator and the third because of employment changes used in the denominator. ${ }^{6}$

We expect there to be less measurement error in the 3-year average and 11-year average fatality rates relative to the annual rate because the averaging process will reduce the influence of random fluctuations in fatalities as well as mitigate the small sample problems that arise from many narrowly defined job categories. However, we also expect less reporting error in the worker industry information than in worker occupation information, so even our annual measure should lead to less measurement error than if the worker's occupation were the primary basis for the matching. ${ }^{7}$

\footnotetext{
${ }^{6}$ For the measures we used the bi-annual employment averages from the U.S. Bureau of Labor Statistics, Current Population Survey, unpublished table, Table 6, Employed Persons by Detailed Industry and Occupation for 1993-2001.

${ }^{7}$ Brown (1980) examined compensating differentials for fatality risks and other job attributes using the NLSY along with risk measures for relatively high-risk jobs from the 1967 Society of Actuaries. Each of the job attribute measures that Brown used were for a point in time. Our fatality risk measures are time dependent and more refined in that more recently available data make it possible to construct risk measures by occupation and industry. For further discussion of the measurement issue, see Mellow and Sider (1983) and Black and Kniesner (2003).
} 
Table 1 lists the mean and standard deviation for the three fatality risk measures. The sample mean fatality risk of 5.9/100,000 is similar across all three measures. As expected, the variation in the annual measure exceeds that of the 3-year and 11-year averages.

A problem plaguing past attempts to estimate the wage-fatal risk tradeoff in panel data has been the use of aggregate fatality rates by industry or occupation because once the researcher applied the within transformation or the first-difference transformation there was little variation left in the fatality risk measure to identify credibly the fatality parameter. Most of the variation in aggregate fatal risk is between-groups (across occupations or industries) and not within-groups, but identification in the within and firstdifference estimators requires within-groups variation. In Table 2 we decompose the variation in our three fatal risk variables into its between-group and within-group components. Although cross-group variation exceeds within-group variation, the within variation is sufficiently substantial (60-70 percent of the between variation) so that we are optimistic that we can identify the fatal risk parameter and VSL in our panel data models.

\section{Wage Equation Estimates}

We record our estimates of the wage fatal-risk tradeoff in Tables 3 and 4, along with the implied value of a statistical life evaluated at the sample mean real wage of $\$ 21$. Although we suppress the coefficients for ease of presentation, each model controls for a quadratic in age, years of schooling, indicators for region, marital status, union status, race, one-digit occupation, and year effects. 
Because of the substantial heterogeneity of jobs in different occupations the regressions include a set of one-digit occupation dummies. The equations do not include industry dummy variables as well because it would introduce multicollinearity with respect to the fatality risk variable, which involves matching workers to fatality risk based on their industry and occupation. Indeed, including two-digit industry dummies in addition to occupation controls will remove all variation in the fatality risk variable. Moreover, the reported standard errors are clustered by industry and occupation. ${ }^{8}$ Finally, our first-difference regressions automatically net out the influence of industry and other job characteristics that do not change over time.

\subsection{Focal Estimates: First-Differences}

Our first-difference estimates from equation (2) appear in Table 3. Comparing estimates down a column reveals the effect of measurement error. The results are reasonable from both an econometric and economic perspective and provide the basis for our research issue, which is how badly VSL can be mis-estimated if certain basic econometric issues are mis-handled.

The VSL implied by the coefficient for the annual fatality rate in Table 3 is $\$ 5.3$ million. A novel aspect of our research is that it may help identify the size of possible measurement error effects. If measurement error in fatality risk is random it will attenuate coefficient estimates and should be reduced by letting the fatality rate encompass wider and wider time intervals. Compared to VSL from the more typical annual risk measure, estimated VSL in Table 3 is about $15-20$ percent larger when fatality risk is a three-year

\footnotetext{
${ }^{8}$ Standard errors for the pooled times series cross-section estimator and the first-difference estimator are robust to heteroskedasticity and within industry-by-occupation autocorrelation; the standard errors for the random-effects estimator are robust to within-person autocorrelation.
} 
average rather than the more typical annual measure and is about 25-33 percent larger when fatality risk is an 11-year average. ${ }^{9}$

The last two columns of Table 3 report the results from dynamic first-difference regressions. The short-run effects from the dynamic model in column 2 are best interpreted as controlling for additional heterogeneity and serial correlation relative to the static results in column 1 . The static and dynamic short-run estimates of VSL differ by no more than about 10 percent. The last column of Table 3 reports the long-run (steady state) estimates. Note that our first-differences estimator focuses on changes in wages in response to changes in risk. The mechanism by which the changes will become reflected in the labor market hinges on how shifts in the risk level will affect the tangencies of the constant expected utility loci with the market offer curve. To the extent that the updating of risk beliefs occurs gradually over time, which is not unreasonable because even release of the government risk data is not contemporaneous, one would expect the long-run effects on wages of changes in job risk to exceed the short-run effects. Limitations on mobility will reinforce a lagged influence. As would be expected, the long-run estimates of VSL in Table 3 are larger than the short-run estimates by about a third to a half. ${ }^{10}$

\footnotetext{
${ }^{9}$ By comparison to the VSL estimates in Table 3, estimates based on the within-estimator yield a VSL of $\$ 4.9$ million with the annual fatality risk, $\$ 5.3$ million with the 3-year average fatality risk, and $\$ 6.2$ million for the 11-year average fatality risk. The within estimates are likely attenuated relative to the wider (2-year) differences reported in Table 3 because of greater measurement error in the deviation from time-mean transformation. The results in the first column of Table 3 remain statistically significant if one-digit industry controls are included, with VSL values of $\$ 3.3$ million, $\$ 4$ million, and $\$ 4.4$ million. For a review of the literature on industry controls in compensating wage differentials research see Viscusi and Aldy (2003, pp. 16-17).

${ }^{10}$ In addition to the twice-lagged level of the log wage, the instruments include the $(\mathrm{t}-1)$ and $(\mathrm{t}-2)$ levels of age, age squared, occupation, marital status, union status, and region. The first-stage $F$-statistic on the identifying instruments is 14 with a $p$-value $<0.000$, suggesting that our dynamic estimates do not suffer from the common problem of weak instruments.
} 


\subsection{Results From Comparison Estimators}

Table 4 presents the comparison models. The first comparison we mention is to the canonical cross-sectional estimates in column 1 . The estimated annual fatal risk parameter yields an implied VSL of about $\$ 16$ million, which is within the range of estimates summarized in Aldy and Viscusi (2003), albeit at the high end of the range, as is often the case for studies using the PSID. Using the smoothed average fatality rates raises the estimated VSL to $\$ 17.0$ and $\$ 17.7$ million for the 3-year and 11-year fatality measures. Even in the pooled cross section, which ignores the latent heterogeneity that have concerned many other researchers, the annual fatal risk measure attenuates the estimated VSL by upwards of 10 percent.

Column 2 of Table 4 reports estimates from the between-groups estimator. The between-groups estimator should mitigate the effects of measurement error in the fatality measures relative to the pooled cross-section estimator. The estimated coefficient on the fatality risk increases by about 40 percent, and the attendant mean estimate of the VSL is about $\$ 23$ million, which is about 6 times larger than our econometrically preferred estimates in Table 3.

Column 3 of Table 4 reports estimates from the random-effects estimator. Recall that the random-effects estimator accounts for unobserved heterogeneity, which is assumed to be uncorrelated with observed covariates. It is fairly common in labor-market research to reject the assumption of no correlation between unobserved heterogeneity and observed covariates, and we find a similar rejection here. ${ }^{11}$ Allowing for the possibility of unobserved productivity and preferences for risk, even if it is improperly assumed to be

\footnotetext{
${ }^{11}$ The Hausman Test of the null hypothesis of random effects is soundly rejected in favor of fixed effects with a $P$-value of less than 0.000 .
} 
randomly distributed in the population, reduces the estimated VSL by $50-55$ percent relative to a model that ignores latent heterogeneity (the pooled least squares estimates). The difference in estimated VSL is consistent with the theoretical prediction in Shogren and Stamland (2002) that failure to control for unobserved skill results in a potentially substantial upward bias in the estimated VSL.

\section{Conclusion and Policy Implications}

Obtaining reliable estimates of compensating differential equations has long been challenging because of the central role of individual heterogeneity in affecting both the market offer curve and individual preferences. The often conflicting influence of different unobservable factors has led to competing theories with opposite predictions; Hwang, Reed, and Hubbard's (1992) unobservable productivity leads to upwardly biased VSLs and Shogren and Stamland's (2002) unobservable safety-related skill and preferences generate a downward bias. Each article presents illustrative estimates indicating that the extent of the bias could be considerable. The direction and extent of the bias can best be resolved with an empirical test that accounts for unobservable individual differences.

The first-difference estimation results reported here use more refined fatality risk measures than used in earlier panel studies, making it possible to control for fixed effects and to identify the wage-fatality risk tradeoff. Comparison of the first-difference results with the pooled time-series cross-section estimates and the between-group estimates implies that controlling for fixed effects reduces the estimated VSL by more than half in every instance, and often by much more. Taking into account the influence of individual heterogeneity implies that, on balance, unobservable safety-related skill and risk preferences are a more powerful influence than unobservable productivity generally. 
Whereas previous studies using the Panel Study of Income Dynamics have often yielded extremely high VSL estimates, earlier research did not control for fixed effects. The first-difference estimates most closely paralleling the models in the existing literature range from $\$ 5.3$ million to $\$ 6.7$ million, which are at or below the median value of the estimates in the literature. Our estimates call into question the very high published VSL estimates, which may reflect the influence of omitted unobservable effects. 
Table 1: Selected Summary Statistics

\begin{tabular}{|c|c|c|}
\hline & Mean & $\begin{array}{l}\text { Standard } \\
\text { Deviation }\end{array}$ \\
\hline Real Hourly Wage & 21.043 & 13.352 \\
\hline Log Real Hourly Wage & 2.880 & 0.570 \\
\hline Age & 40.895 & 8.449 \\
\hline Marital Status (1=Married) & 0.820 & 0.384 \\
\hline Race (1=White) & 0.763 & 0.425 \\
\hline Union (1=member) & 0.230 & 0.421 \\
\hline Years of Schooling & 13.584 & 2.216 \\
\hline Live in Northeast & 0.177 & 0.381 \\
\hline Live in Northcentral & 0.288 & 0.453 \\
\hline Live in South & 0.372 & 0.483 \\
\hline Live in West & 0.163 & 0.370 \\
\hline \multicolumn{3}{|l|}{ One-Digit Industry Groups: } \\
\hline Mining & 0.008 & 0.087 \\
\hline Construction & 0.106 & 0.308 \\
\hline Manufacturing & 0.259 & 0.438 \\
\hline Transportation and Public Utilities & 0.109 & 0.311 \\
\hline Wholesale and Retail Trade & 0.130 & 0.336 \\
\hline Fire, Insurance, and Real Estate & 0.045 & 0.208 \\
\hline Business and Repair Services & 0.066 & 0.248 \\
\hline Personal Services & 0.010 & 0.101 \\
\hline Entertainment and Professional Services & 0.169 & 0.375 \\
\hline Public Administration & 0.098 & 0.298 \\
\hline \multicolumn{3}{|l|}{ One-Digit Occupation Groups: } \\
\hline Executive and Managerial & 0.186 & 0.389 \\
\hline Professional & 0.162 & 0.368 \\
\hline Technicians & 0.058 & 0.234 \\
\hline Sales & 0.032 & 0.177 \\
\hline Administrative Support & 0.066 & 0.248 \\
\hline Services & 0.086 & 0.280 \\
\hline Precision Production Crafts & 0.207 & 0.405 \\
\hline Machine Operators & 0.077 & 0.267 \\
\hline Transportation & 0.080 & 0.272 \\
\hline Handlers and Labors & 0.046 & 0.209 \\
\hline Annual Fatality Rate (per 100,000 ) & 5.924 & 9.096 \\
\hline 3-Year Fatality Rate (per 100,000) & 5.811 & 8.569 \\
\hline 11-Year Fatality Rate (per 100,000 ) & 5.870 & 8.567 \\
\hline \multicolumn{3}{|l|}{ Number of Men $=2,108$} \\
\hline Number of Person Years $=7,937$ & & \\
\hline
\end{tabular}


Table 2: Between and Within Group Variation for Industry by Occupation Fatality Rates

\begin{tabular}{lccc} 
& $\begin{array}{c}\text { Overall } \\
\text { Standard } \\
\text { Deviation }\end{array}$ & $\begin{array}{c}\text { Between } \\
\text { Group } \\
\text { Standard } \\
\text { Deviation }\end{array}$ & $\begin{array}{c}\text { Within } \\
\text { Group } \\
\text { Standard } \\
\text { Deviation }\end{array}$ \\
\cline { 2 - 4 } $\begin{array}{l}\text { Annual Fatality Rate } \\
\text { (per 100,000) }\end{array}$ & 9.096 & 7.766 & 5.309 \\
$\begin{array}{l}\text { 3-Year Fatality Rate } \\
\text { (per 100,000) }\end{array}$ & 8.569 & 7.621 & 4.628 \\
$\begin{array}{l}\text { 11-Year Fatality Rate } \\
\text { (per 100,000) }\end{array}$ & 8.567 & 7.693 & 4.575 \\
\hline
\end{tabular}




\section{Table 3: Static and Dynamic First-Difference Estimates of Wage-Fatal Risk Tradeoff}

\begin{tabular}{|c|c|c|c|}
\hline & $\begin{array}{c}\text { Static First-Difference } \\
\text { Estimates }\end{array}$ & \multicolumn{2}{|c|}{ Dynamic First-Difference Estimates } \\
\hline & & Short-Run Effect & Long-Run Effect \\
\hline Annual Fatality Rate & $\begin{array}{c}0.0013 \\
(0.0004)\end{array}$ & $\begin{array}{c}0.0014 \\
(0.0005)\end{array}$ & $\begin{array}{c}0.0019 \\
{[0.0084]}\end{array}$ \\
\hline Implied VSL (\$Millions) & 5.3 & 5.8 & 8.1 \\
\hline 3-Year Fatality Rate & $\begin{array}{c}0.0015 \\
(0.0005)\end{array}$ & $\begin{array}{c}0.0014 \\
(0.0006)\end{array}$ & $\begin{array}{c}0.0020 \\
{[0.0284]}\end{array}$ \\
\hline Implied VSL (\$Millions) & 6.2 & 5.9 & 8.3 \\
\hline 11-Year Fatality Rate & $\begin{array}{c}0.0016 \\
(0.0005)\end{array}$ & $\begin{array}{c}0.0017 \\
(0.0007)\end{array}$ & $\begin{array}{c}0.0024 \\
{[0.0165]}\end{array}$ \\
\hline Implied VSL (\$Millions) & 6.7 & 7.3 & 10.3 \\
\hline Number of Observations & 5250 & 3379 & 3379 \\
\hline
\end{tabular}

Notes: Standard errors are recorded in parentheses and $p$-values of the null hypothesis that the long-run effect is zero are recorded in square brackets. Standard errors for the first difference estimator are robust to heteroskedasticity and within industry-by-occupation autocorrelation. Each model controls for a quadratic in age, years of schooling, indicators for region, marital status, union status, race, one-digit occupation, and year effects. 


\section{Table 4: Cross Section and Panel Data Estimates of Wage-Fatal}

Risk Tradeoff

\begin{tabular}{cccc} 
& & & \\
\cline { 2 - 4 } & $\begin{array}{c}\text { Pooled Cross } \\
\text { Section Time } \\
\text { Series Estimator }\end{array}$ & $\begin{array}{c}\text { Between-Group } \\
\text { Estimator }\end{array}$ & $\begin{array}{c}\text { Random-Effects } \\
\text { Estimator }\end{array}$ \\
\cline { 2 - 4 } Annual Fatality Rate & 0.0038 & 0.0054 & 0.0016 \\
& $(0.0010)$ & $(0.0017)$ & $(0.0005)$ \\
Implied VSL (\$Millions) & 16.0 & 22.8 & 6.9 \\
3-Year Fatality Rate & 0.0041 & 0.0051 & 0.0019 \\
Implied VSL (\$Millions) & 17.0 & $(0.0017)$ & $(0.0006)$ \\
11-Year Fatality Rate & $0.0011)$ & 21.3 & 7.8 \\
& $(0.0010)$ & $(0.0017)$ & $(0.0006)$ \\
Implied VSL (\$Millions) & 17.7 & 21.1 & 8.5 \\
Number of Observations & 7937 & 2108 & 7937 \\
\hline
\end{tabular}

Notes: Standard errors are recorded in parentheses. Standard errors for the pooled times series cross-section estimator and the first difference estimator are robust to heteroskedasticity and within industry-by-occupation autocorrelation.

Each model controls for a quadratic in age, years of schooling, indicators for region, marital status, union status, race, one-digit occupation, and year effects. 


\section{References}

Abowd, J. and D. Card (1989). "On the Covariance Structure of Earnings and Hours Changes." Econometrica 57(2): 411-445.

Arellano, M. (1989). "A Note on the Anderson-Hsiao Estimator for Panel Data." Economics Letters 31(4): 337-341.

Black, D.A., and T.J. Kniesner. (2003). "On the Measurement of Job Risk in Hedonic Wage Models." Journal of Risk and Uncertainty 27(3): 205-220.

Brown, C. (1980). "Equalizing Differences in the Labor Market." Quarterly Journal of Economics 94(1): 113-134.

Ekeland, I., Heckman, J.J. and L. Nesheim. (2004). "Identification and Estimation of Hedonic Models.” Journal of Political Economy 112(1, pt. 2): S60-S109.

Griliches, Z. and J.A. Hausman. (1986). "Errors in Variables in Panel Data." Journal of Econometrics 31(1): 93-118.

Hwang, H., Reed, W.R., and C. Hubbard. (1992). "Compensating Wage Differentials and Unobserved Productivity.” Journal of Political Economy 100(4): 835-858.

Keane, M.P. (1993). "Individual Heterogeneity and Interindustry Wage Differentials." Journal of Human Resources 28(1): 134-161.

Lang, K., and S. Majumdar. (2004). "The Pricing of Job Characteristics When Markets Do Not Clear: Theory and Policy Implications." International Economic Review 45(4): 1111-1128.

MaCurdy, T.E. (1982). "The Use of Time Series Processes to Model the Error Structure of Earnings in a Longitudinal Data Analysis." Journal of Econometrics 18(1), 83114.

Mellow, W., and H. Sider. (1983). "Accuracy of Responses in Labor Market Surveys: Evidence and Implication.” Journal of Labor Economics 1(4): 331-344.

Shogren, J.F. and T. Stamland. (2002). "Skill and the Value of Life." Journal of Political Economy 110(5): 1168-1173.

Thaler, R., and S. Rosen. (1975). "The Value of Saving a Life: Evidence from the Labor Market." In N.E. Terleckyj (ed.), Household Production and Consumption. New York: Columbia University Press, pp. 265-300.

Viscusi, W.K. (2004). "The Value of Life: Estimates with Risks by Occupation and Industry." Economic Inquiry 42(1): 29-48. 
Viscusi, W. K., and J. Aldy. (2003). "The Value of a Statistical Life: A Critical Review of Market Estimates throughout the World." Journal of Risk and Uncertainty 27(1): $5-76$.

Viscusi, W.K. and J. Hersch. (2001). "Cigarette Smokers As Job Risk Takers." Review of Economics and Statistics 83(2): 269-280.

Wooldridge, J.M. (2002). Econometric Analysis of Cross-Section and Panel Data. Cambridge, MA: The MIT Press.

Ziliak, J.P. and T.J. Kniesner. (1998). "The Importance of Sample Attrition in Life-Cycle Labor Supply Estimation.” Journal of Human Resources 33(2): 507-530. 